\title{
Influence of cultural mechanisms on horizontal inter-firm collaborations
}

\author{
José R. Vilana, Carlos Rodríguez-Monroy \\ Universidad Politécnica de Madrid (SPAIN) \\ joseramon.vilana@bystronic.com;.crmonroy@etsii.upm.es
}

Received September 2009

Accepted June 2010

Abstract: The evolution of organizations that work in multinational environments has considerably altered their production strategies. One of the consequences has been the appearance of Horizontal Inter-firm Collaborations (HICs), which include all kinds of enterprises and production centres and establish a new type of horizontal collaborations and relations between independent companies or even competitors who establish occasional collaborations on projects they could not take on individually. HICs are dynamically changing organizations formed by Original Equipment Manufacturers (OEMs), Contract Manufacturers (CMs), turn-key and component suppliers, $\mathrm{R}+\mathrm{D}$ centres and distributors. The dynamic relations that exist within the HICs allow them a very permeable organization easy to connect and disconnect from one to each other as well as to choose a set of partners with specific attributes. The result is a highly flexible system characterized by low barriers to entry and exit, geographic flexibility, low costs, rapid technological diffusion, high diversification through contract manufacturers and exceptional economies of scale. This study of organizational culture at the network level includes aspects such as cultural similarity among its actors, social embeddedness, tacit knowledge transfer or the importance of trust atinter-firm collaborations. The presence, under a systemic perspective, of homogeneous cultural values and practices in which collaboration actors can be identified may strengthen the group membership or establish a social network that underlies the own HIC and facilitates interactions among its members. The feasibility of this approach would facilitate the formation of new HICsby establishing, ex ante, a cultural prescriptive model at the network level. Finally, to validate the proposed 
model, the case methodology have been applied to an example within the aeronautical industry that has been one of the most successful relationships within HICs, the collaboration between GE and SNECMA for the CFM 56 engine manufacturing.

Keywords: horizontal inter-firm collaborations, aeronautic industry, GE, SNECMA

\section{Introduction}

Today, the concept of plant or production centre is becoming increasingly more ambiguous. In many industries, there is growing collaboration between production centres and manufacturing networks that seek to respond to market demands more efficiently and obtain competitive advantages in an increasingly globalized environment.

Horizontal Inter-firm Collaborations (HICS) allow companies to focus on their core competences, maintaining their participation in the design and manufacture of complex integrated systems. These collaborations can be considered as extended manufacturing systems where various companies can co-operate on a specific project whose result is the manufacture of a product or the provision of a service and where each company is expert in one or more of the areas that give the product its value. Although there are hardly any theoretical models or studies on how these networks function, they are known to develop on a large scale and involve a complex number of participants that include enterprises, organizations and institutions covering several countries or even continents.

\section{THEORETICAL FRAMEWORK OF CULTURAL MECHANISMS IN HORIZONTAL INTER-FIRM COLLABORATIONS}

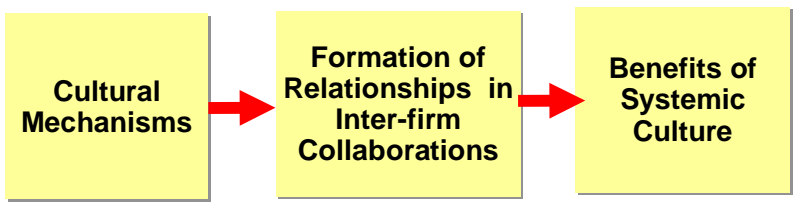

Figure 1. "Theoretical framework of cultural mechanisms in HICs".

This work will analyze the possible existence of an organizational culture at the network level based on some cultural mechanisms acting under a systemic 
perspective that influence the success or survival of inter-firm collaborations. The hypothesis of the existence of a homogeneous culture in the HIC where actors can be identified would strengthen the group membership, minimize inter-company conflicts or increase the interactions among its members.

Figure 1 contains basic aspects of the conceptual model to be developed where some cultural mechanisms influence in the dynamics of HICs. This work will analyze the nature of these mechanisms, their influence on the construction of these networks and their mutual interaction. Albeit true origins of these mechanisms are based on the traditional principles of organizational culture, its dynamics in HICs is considerably different. These mechanisms, in some cases, underlie some organizations even before the formation of relationships (ex ante mechanisms) and, in other cases, arise subsequently to the formation of the relation and exert a considerable influence in it (ex post mechanisms). The effect of these mechanisms, if well managed, can produce significant benefits in their own HIC which will result in an increase on its efficiency.

Section 2 of this work includes the most interesting contributions of the literature concerning Horizontal Inter-firm Collaborations (HICs)and corporate culture. Sections 3, 4, 5 and 6 develop the four nominated cultural mechanisms that are similarity of cultural practices, social embeddedness, trust and tacit knowledge transfer. The proposed conceptual model is developed in section 7 as well as the mutual influence of these cultural mechanisms and the benefits of a systemic culture. To validate the model proposed, section 8 applies the case methodology to one of the most successful examples of horizontal cooperation in the aeronautical industry, the CFM 56 engine manufacturing collaboration between GE and SNECMA, where it is analyzed the importance of the four nominated cultural mechanisms. Finally, section 9 summarizes the most relevant contributions of this work as well as some proposals for further developments in this field.

\section{Literature review}

The concept of culture applied to business organizations is not new. Although many authors (e.g. Schein, 1985 and Trice \& Drink, 1993) have developed approaches and theories to suit organizational culture to new business environments, the underpinning on which they are based do not seem radically different to those 
adopted by Mayo (1930) to explain the concept of informal organization with their experiment in the Hawthorne plant. Subsequently, many authors have referred to this concept in the theory of organizations as one of the most relevant ones. Hofstede et al. (1990) argue that organizational culture has acquired a status similar to the structure, strategy and control.

Although there is no consensus on a definition of organizational culture, many authors agree that it is a holistic concept, historically determined, related to anthropological aspects, built on social relations, based on soft aspects and it is difficult to change once implemented. The utility or usefulness of organizational culture is one of the most recurrent themes in the theory of organizations. According to several authors (e.g. Pothukuchi et al., 2002 and Trice \& Drink, 1993), the need for a corporate culture in an enterprise is evident since facilitates internal cohesion, aligns its members with the mission and objectives of the company, resolve internal conflicts, lead and shape attitudes and behaviours and establish organizational boundaries to differentiate the own organization from others.

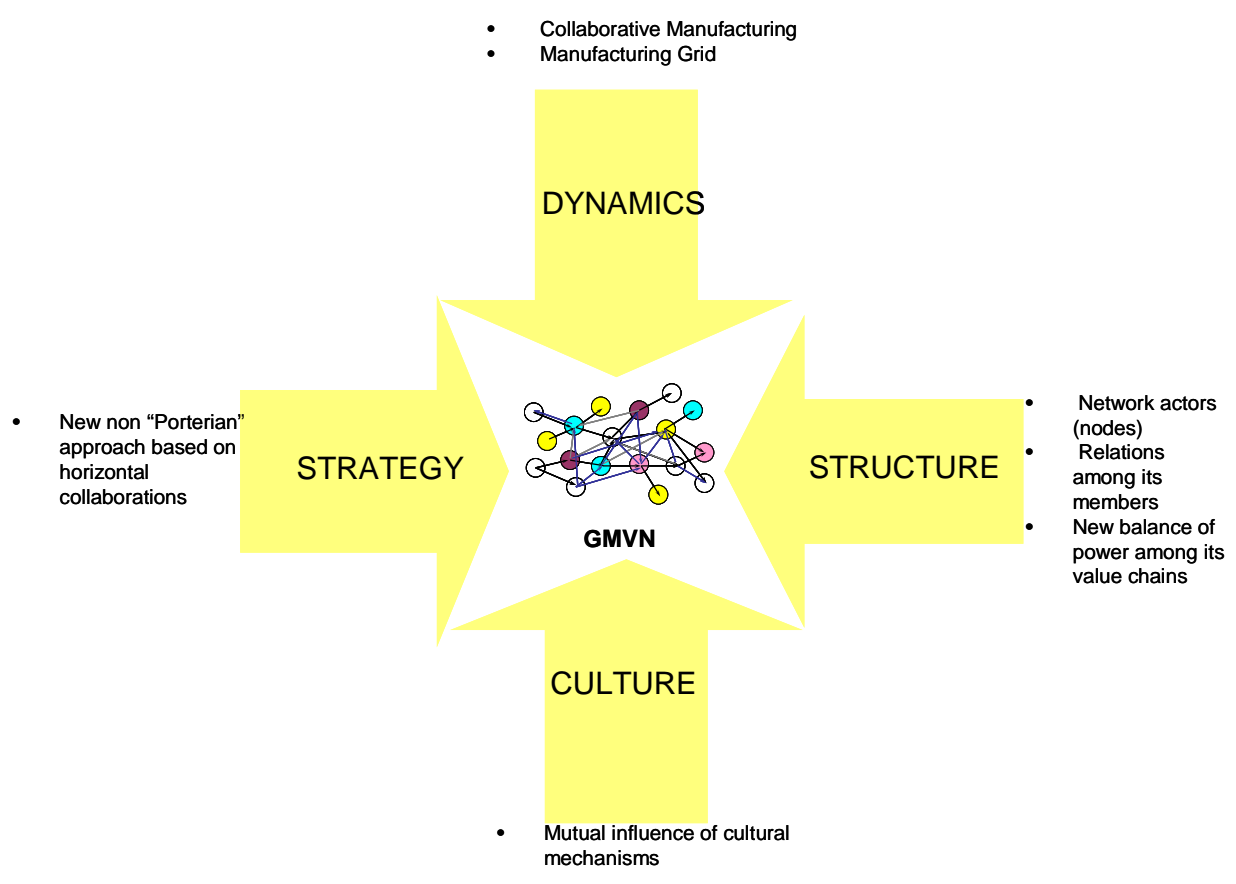

Figure 2. "Basic aspects of HICs".

Within the context of HICs, the necessity or functionality of a systemic culture presents a more complex dilemma. The heterogeneity of network actors, their 
diverse backgrounds and their different roles and interests seem to contradict the fundamentals of the organizational culture. At the same time, it seems plausible the existence of some cultural mechanisms that underlie the network and act as elements that facilitate interactions between enterprises. The effect of organizational culture on enterprise networks performance has been studied by many authors (e.g. Brown et al., 1988; Park \& Ungson, 2001; Pothukuchi et al., 2002; Hofstede, 2009) where the vast majority affirms that cultural differences between network actors affects negatively their performance.

In the late '80s and early '90s, due to the intense and growing global market demand, many companies seriously considered the benefits of interconnected production networks. In some industries such as aeronautics (Shi et al., 2005), electronics (Shi et al., 2003) or automotive (Sturgeon, 2002), HICs have become a phenomenon of important growth with high potential to meet an ever more demanding and fragmented market (Shi et al., 2003). Many scholars have studied this phenomenon from different perspectives. Under a strategic perspective, HICs follow different patterns to the traditional and endogamic "Porterian" approach (Porter, 1996) based on searching a balance of forces in the sector and on achieving a sustainable competitive advantage over time. Because of the strong component of horizontal relationships between competitors that exists in these networks, researchers have sought new ways of analysis like structural (Chen \& Yao, 2003) or emotional mechanisms (Zeng \& Chen, 2003; Gulati \& Nickerson, 2008).

Under a strategic perspective, some authors have analyzed the search of a competitive advantage at the network level based on a global view, where the fit of activities based on the combination of specific skills allow HICs to effectively compete in the market (Hoopes, 2003). A variant of this approach is what Doz and Hamel (1998) called "cospecialization" by proposing that actors should specialize in complementary activities to those of other network members in order to avoid redundancies or excessive overlaps, and thus optimize the value creation in the network (Vilana \& Rodríguez-Monroy, 2009a). Other relevant works about these organizations were made by Johansen (2005) who analyzed the production strategy change of the aeronautical manufacturer SAAB AERO to join the Airbus manufacturing network. Meixell (2004) studied the convergence of these organizations with mass customization systems and Williams et al. (2001) 
surveyed the relations among supply chain members and offset strategies in the global aerospace sector.

Also from the perspective of its dynamics, Li et al (2004) analyzed manufacturing grids or collaborative manufacturing networks which have a strong presence in sectors such as computer manufacturing, astronomy and bioinformatics (Liu \& Shi , 2008). These works study how to coordinate the use of heterogeneous and independent manufacturing resources distributed throughout the network. Recently, several authors have developed conceptual models referred to the organization of information and communication technologies (ICTS) needed in this type of organization (e.g. Camarinha et al., 2009; Chituc et al., 2008). However, there are still many aspects to develop in this field like the development of a comprehensive ICT prescriptive model that can manage HICs or if it is necessary or not to direct these networks.

Anyhow, some research fields need further development like collaborative strategies among network actors or cross-cultural attributes at network level. Future works should also deep into a comprehensive understanding of all HICs features and their interdependence. By understanding the main building blocks of these organizations and their management processes, it will be possible to formulate a strategy and design process for developing effective HICs in the future. The graph in Figure 2 sets out a basic outline that includes the four building blocks that encompass all relevant aspects of HICs: strategy, structure, dynamics and culture.

\section{Similarities of cultural practices between network actors}

It seems that there is a general consensus among most of scholars (e.g. Pothukuchi et al., 2002; Park \& Ungson, 2001) about the importance of cultural similarities in inter-firm collaborations to conclude that participants with similar cultural values reach high assessments of satisfaction, learning and collaboration efficiency. While cultural differences among its actors hinder learning, satisfaction and efficiency of collaboration. Culture acts as a "social glue" (Cartwright \& Cooper, 1993) that serves as a union between persons of different organizations to create, subsequently, a cohesion between companies. Different types of organizational culture create different psychological environments in alliances so that cultural 
differences lead them to cause a negative influence on their performance (Beugelsdijk et al., 2009). Therefore, we can affirm that the degree to which fits the organizational culture of the companies forming part of an alliance is directly related to the success of it. Companies participating in a partnership with strong differences in their organizational culture must spend enormous energy and time to establish management practices and organizational routines that facilitate the interaction which can lead to high costs and loss of trust compared to companies similar culturally (Park \& Ungson 1997).

The problem arises when specifying what cultural similarities are necessary, what mechanisms or aspects of organizational culture are more relevant when measuring the efficiency of collaborations. Besides, cultural values that according to many authors are the essence of organizational culture are not easily discernible in a company and are unlikely to be detected before starting collaboration. Although many authors (e.g. Deal \& Kennedy 1982, Schein, 1985) argue that values are the essence of organizational culture and that these can not be known explicitly, Hofstede et al. (1990) argue that cultural practices are as they are perceived in the daily routine, the heart of an organizational culture. That is, the values of the leaders become practices shared by members of the organization transmitted by socialization. Empirical studies conducted by Hofstede et al. (1990) show that cultural values differ more between individuals with different demographic characteristics, age, nationality and education regardless of the organization in which they work. In addition also showed that people who belong to different organizational cultures (different companies) often have different cultural practices but may share similar cultural values. This is because, as Hofstede et al. (1990) argue, cultural values are acquired in the first years of life, in the family and educational environment, while organizational practices acquired in the workplace through socialization.

Under this approach, cultural practices are those that determine organizational culture rather than its values. Therefore, it is essential that there is some degree of similarity in these practices when formalizing inter-firm relations. Differences in cultural values related to national culture, education or family background do not pose insurmountable obstacles in the collaboration between companies. Subsequent studies endorsed this new approach as Park and Ungson (1997) who 
explore how partnerships between companies from different nationalities have no influence with the alliance failure rate.

A classification of these cultural practices would be the proposal of Hofstede (2009) who suggest six key practices within an organization that distinguish their management approach. When different companies that must work together show great differences in these practices conflicting behaviours arise and adversely affect the collaboration. These management practices include 1) process-oriented vs. results-oriented, 2) employee-oriented vs. job-oriented, 3) amateur vs. professional; 4) open systems vs. closed systems; 5) loose vs. tight control and 6) pragmatic versus normative.

In a HIC, differences in these cultural practices among companies who intensively collaborate can signify an overwhelming obstacle since means an opposite way of looking at activities in an organization such as internal communication, achievement of objectives, career system or formal and informal structure which is a conflict in the performance of the duties, expectations and practices.

Therefore, we can affirm that the basis of an organizational culture at a HIC should avoid a high degree of incompatibility in their cultural practices. This fact will make more efficient the cooperation between its members and will avoid losing large amounts of energy and resources to bridge these differences. Although, it is not necessary to prevent these differences in their values that depend more on the type of context the network actors work and develop such as education or national environments. This would ensure the efficiency of interaction among its members or even the survival of the network itself.

The problem arises when, once HIC collaboration is formalized, strong inconsistencies are detected in one or more cultural practices described above. In fact, it is exceptional to find a company with which is wished to establish a partnership and there is a strong compatibility and similarity of all cultural practices. Cultural practices do not constitute a cause of such collaboration but are a necessary condition for its success. The collaboration between GE and SNECMA for the aircraft engine manufacturing CFM 56, partially solved this dilemma by constituting, ad hoc, some new departments and internal processes, identical in both companies, exclusively related to the new program for developing the CFM engine. This measure allowed the formation of subcultures in these departments 
with high degree of cultural practices similarity between the two companies. Later, it was formed a new company $50 \%$ owned by each participant which facilitated the cultural compatibility in their practices. Another example, the aeronautical consortium EADS formed by aeronautical Aerospatiale-Matra (France), DASA (Germany) and CASA (Spain) in order to solve the significant differences in the corporate culture of their parent companies, pursued a human resources policy aimed to build a "spirit of EADS" who worked on the harmonization and integration of all staff. Besides, the addition of 1,500 new workers facilitated the consolidation of a new corporate culture (Barmeyer \& Mayrhofer, 2008). Undoubtedly, these measures inculcated through socialization helped to build new similar cultural practices that were the basis of the new corporate culture of EADS.

Proposition 1: Similarity of cultural practices between actors in HICs increases chances of survival and constitutes an ex ante cultural mechanism that favours the existence of homogeneous culture in the network.

\section{Social embeddedness in HICs}

According to Gulati (1995), the formation of business networks is immersed in a rich social context that conditions the future collaboration. The previous relationships create a social network in which the companies are integrated and represent a source of invaluable information about the reliability and capacity of current and potential participants in the network, improving information on new opportunities and trust among current and potential actors involved in it. This social network is a dynamic system formed by the experience of past relationships, current partners and evolves over time as establishing new alliances forming an active interaction between action and structure of the network that influences the attitude of his actors. Under this approach, previous social networks condition the collaborations between companies which are based on past experience to establish new relationships, which affect the social structure of the network and causing a continuous mutual influence between structure and strategy.

Although the origin of this approach is grounded in the classical psychological theory, the idea that economic action is embedded in social networks was revitalized by Granovetter (1985) who stated that economic activities rest on the widespread preference for dealing with individuals of distinguished reputation 
based on trust informants who have previously dealt with them or based on personal experiences with these potential partners. These findings were confirmed by Gulati and Sytch (2008) which stressed the importance of previous relations in the HICs as an invaluable source of reliable information on skills, availability and reliability of potential partners.

In the context of HICs, the importance of social relationships is magnified because during business transactions in the network, the relational capital can be, in many cases, more valuable than the economic capital (Luo 2001). New companies that enter in HICs face a high risk of opportunistic behaviour due to unpredictable behaviour of potential partners and the high costs that such conduct would incur if materialized (Kogut 1988). A new partner of a HIC could act freely within the network by acquiring all the resources, limiting his contributions or simply acting opportunistically and taking advantage of close relationships to use the resources and information in his own interest. This situation will cause a source of uncertainty stemming from the lack of information on the reliability of potential collaborator whose conduct is a key factor in the success of the alliance.

Therefore, social embeddedness gives information to the stakeholders of HICs on skills, needs and competencies of potential new collaborations in the network and increases reliability against potential opportunistic behaviour. In addition, previous relationships between two actors constitute an invaluable source of information about future collaborations or references to other members of the HIC. These social networks need time to settle and once established they will act as a catalyst for business relations in the network. To know the map of social relationships on the network is a key factor to succeed in HICs. It is very complex to start a close collaboration from the beginning if there is not a previous experience of less demanding relationships that allow constructing a network of embedded social relations in the HIC. So the virtualization of HICS will be directly related to the intensity of previous social relations in the network. By degree of virtualization is understood the intensity of partnerships with companies outside of the organization itself (Shi et al., 2003).

Proposition 2: The more intense and enduring are the previous social relations between members of a $\mathrm{HIC}$, the greater the degree of virtualization of the network in the future. 


\section{The importance of trust in networks}

Several authors (e.g.: Gulati and Sytch, 2008) have criticized the approach of the theory of transaction costs in considering each transaction between companies forming an alliance as an independent and unique event regardless of the repetitive nature of these events over time. A key factor that arises in alliances over time and that will determine the structure of future business relationships is trust. Trust, in this context, can be defined as the intention to accept a risk and be vulnerable based on positive expectations for the conduct of the other party (Luo 2001). It can also be seen as a compromise between the parties not to exploit the weaknesses of the other (Steensma \& Lyles 2000) or as Lane and Lyles (2001) state functions as a continuum mechanism of social control and acts as a reducer of risk in business collaborations.

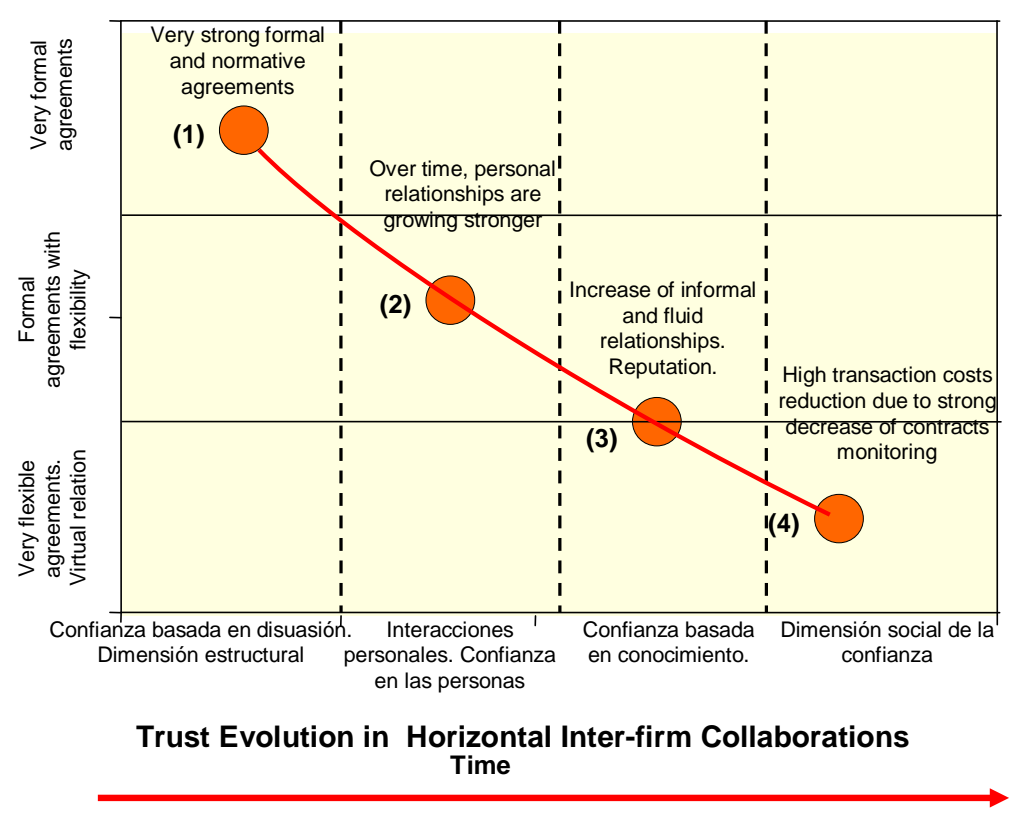

Figure 3. "Relation between Trust and Degree of Virtualization in HICs".

The graph in Figure 3 shows the different phases of trust in relations between companies within a HIC and its relation with the degree of "virtualization." Point 1 is referred as structural trust (Madhok 1995), also called trust based in deterrence (Shapiro et al., 1992) or "hard" trust according to Parkhe (1993). This type of trust is based on the tangible aspects of collaboration and the mutual need to ensure the 
relationship. But it also can use more explicit mechanisms like very strict and formal contracts that include clauses of sanctions or penalties to prevent opportunistic behaviour and, thus, leading actors to a relationship of mutual dependence or mutual hostages. Although this type of trust is essential in the first stages of collaboration, it is not enough for long term relations since it is inherently unstable and does not take into account the relational or social aspect. It depends continuously on the symmetry of short-term contributions of the actors. A typical form of collaboration at this stage is the formation of new companies with joint capital participation (joint ventures) for attempting to avoid or reduce this fear. Anyhow, strict contracts are not always effective if each party pursues opportunistic behaviour (Park \& Ungson, 2001).

Over time, emerging personal relationships create trust through the continuous interaction of people from different companies, as indicated in point 2 of Figure 3. At this stage, the relations in HICs are based on trust rather than on a formal contract. Learn to build that trust between the parties is the most difficult aspect of successful business relationships because people can only trust people. Inter-firm trust is built on personal relations between people from both organizations (Msanjila \& Afsarmanesh, 2008). Although trust is an interpersonal and subjective phenomenon that emerges and evolves between individuals, many authors refer to trust in economic transactions through inter-firm relationships (Gulati \& Sytch, 2008). The fundaments of this trust have a strong cognitive background based on the experience of previous interactions as established by Shapiro et al (1992). It is a knowledge-based trust and appears when network actors develop a mutual understanding in the relationship as indicated in point 3 of Figure 3 . With this type of trust, also called process-based-trust (Lavrac et al., 2007), the network actors increasingly begin to establish more informal relationships, processes are becoming more dynamic and transaction costs are reduced dramatically.

Eventually, trust becomes a very efficient mechanism in the relations between firms. It helps to mitigate problems caused by the strong competition between participants of HIC or due to the organizational complexity of the network. It reduces transaction costs by drastically reducing the design and contract negotiation cost. It facilitates the supervision of the alliance, improves tacit knowledge transfer, further accelerates the search for new partners among network members and helps to solve potential conflicts among its members. This 
stage is the so-called social trust (Madhok, 1995) as indicated in point 4 of Figure 3. It is no longer based on fear of sanctions for opportunistic behaviour or the tangible value that is obtained from the collaboration but on the social side of relationships. At this point, it is not necessary to create new companies with equity investments neither to formalize a relationship nor to design complex contracts that take into account the whole casuistry of the relationship. The collaboration is mainly based on informal relationships based on past experience, which significantly reduces transaction costs. This trust generates over time a stock of conciliation or good intentions that actors can use in times of conflict or tension in the relationship. An example of social trust was the relationship established by Boeing and a consortium of Japanese partners to develop the Boeing 757 aircraft family (Madhok, 1995). Both sides needed each other to share the high development costs and achieve synergies between the experience of Boeing and manufacturing efficiency of the Japanese. But at the beginning of the collaboration, they had to face an unexpected important loss of sales income of the 757 model. Given this scenario, Boeing assigned to his Japanese partners work of other aircrafts to compensate for the fall in revenues as a gesture of commitment although there was no contractual obligation in that regard. This act generated a level of trust that facilitated resolution of later conflicts. The collaboration lasted until the next generation of Japanese aircrafts allowing greater participation than in previous stages.

An interesting aspect of trust in $\mathrm{HICs}$ is the correlation between degree of virtualization and trust level achieved. The greater trust achieved, the less need will be to formalize strict and legal ties between firms that collaborate. Therefore, it can be argued that over time the degree of virtualization in HICs will increase based on a sincere trust built between the companies. In other words, trust and the degree of virtualization increase proportionally over time in the HICs that are successful.

Importance of social trust is magnified in network structures especially in situations of ambiguity where actors can perform a diffused role of collaborator and competitor. This scenario is particularly relevant in HICs. Trust takes time; gradually emerges from successive interactions between the parties as there is reciprocity and symmetry in the contributions. Over time the perceived level of opportunistic behaviour is reduced. The problem that now arises has to be with the 
need of a prescriptive approach that facilitates relations of collaboration. This approach is feasible if a set of guidelines is adequately accomplished to develop inter-firm trust in order to move as quickly as possible through the proposed trust curve. In this sense, companies must invest their resources in improving trust in the early stages of collaboration. They also need to minimize staff rotations so that social relations have continuity and mutual trust is increased. Intense collaborations from the beginning must be avoided knowing that the process of building social trust takes time. Also, the creation of value through complementary capabilities can be used to improve the relationship, absorb additional costs of collaboration and build trust. This idea is what Doz and Hamel (1998) called cospecialization and implies that HIC actors focus on a few key skills and activities that are complementary to those of other network participants. This approach involves improving the knowledge or ability on a specific field and let other network actors to develop the other complementary activities. When these mutually complementary skills are valued, the possibility of future development builds trust and minimizes opportunistic behaviour. Trust is definitely a cultural ex post mechanism in HICs which evolves slowly over time and if the appropriate measures are taken it can dramatically reduce transaction costs, make more fluid business collaboration and facilitate tacit knowledge transfer in the HICs.

Proposition 3: Trust and the degree of virtualization in a HIC increase proportionally with time in HICs that are successful.

Proposition 4: The more cospecialization in a HIC, the greater dissimilarity in technological capabilities and the higher trust level.

\section{Tacit knowledge transfer}

Many scholars in knowledge transfer (e.g. Gupta and Govindarajan, 2000) agree that all companies have knowledge and it is, probably, the strongest source of sustainable competitive advantage over time. One of the main reasons to exist joint ventures is the mutual benefit obtained from tacit knowledge transfer of the other organization that could hardly be obtained independently in the market (Kogut, 1988). This knowledge is deeply embedded in people and it is difficult to codify and communicate openly. It is revealed through their skills, their cognitive ability and their routine work. Dhanaraj et al. (2002) argue that tacit knowledge is 
inclusive, easy to communicate and may be inferred through action allowing a wider and deeper understanding of explicit knowledge. Explicit knowledge is encoded and formally standardized in an organization. It is systematic and can be filed, transmitted and acquired through different mechanisms.

Knowledge transfer in HICs can be done through various mechanisms from detailed formal contracts that establish conditions for such transfer including technical consulting support, technological transfer contracts, licenses, technical support, specifications, technical documentation or supply of equipment to more informal arrangements where there is no explicit action. For example, GE Energy requires that all its maintenance centres throughout the world use a particular type and model of high-tech equipment for surface coatings. This standard equipment has implicitly embedded GE "know how" through uniform equipment parameterization according to internal developments of the company. In this way, GE ensures a minimal learning curve in using this equipment, an immediate diffusion of recent developments and homogeneity in their work. Another example is the case of Knowledge transfer in HICs is positively associated with motivational willingness to share knowledge, the initial stock of knowledge of the actors, the intensity and fluidity of the transmission and the ability to absorb knowledge (Cohen \& Levinthal, 1990).

Tacit knowledge transfer is an ex post cultural mechanism that satisfies many of the demands of HICs. One of the reasons to exist these networks is the ability to transfer and make use of knowledge more efficiently in an environment of alliances rather than through external market mechanisms. Anyhow, this argument does not mean that tacit knowledge is easily transferred through the network since this fact will be determined by the collaborative and competitive position of the network actors. In the proposed model, tacit knowledge is an ex post mechanism that appears after the formalization of the relationship and it is largely influenced by the different competitive and collaborative positions that take the HIC participants. Larsson et al. (1998) study this phenomenon in a dyadic collaboration by applying an adaptation of the prisoner's dilemma through the game theory. Depending on the positioning of each network actor before the knowledge transfer in a dyadic context (e.g. compromise, collaboration or competition), each participant can evolve towards collaboration or opportunistic positions. 
This type of knowledge represents one of the most efficient competitive advantages sustainable over time (Gupta \& Govindarajan, 2000). It is also one of the main factors that help to differentiate companies from each other (Trice \& Beyer, 1993). There are many possibilities that a strong tacit knowledge transfer between two network actors produce a convergence in their cultural practices and consequently this fact will help to homogenize culturally the network. Thus it can be affirmed that tacit knowledge transfer in a HIC can help to build a systemic culture. When a network actor shares with other participants, a kind of knowledge which is one of its most important assets, what determine its own identity and distinguishes it from other enterprises in the network, when this asset is diluted and expanded through the HIC, a process of cultural homogenization start to occur in the network.

Proposition 5: An intense tacit knowledge transfer between HIC actors increases the similarity of cultural practices, helps to homogenize culturally the network and builds a systemic culture.

\section{Conceptual framework of cultural mechanisms in HICs}

Figure 5 shows the conceptual framework that integrates the cultural mechanisms seen previously between whom there is a constant interaction both before the formalization of the partnership and after forming a continuous process where these mechanisms are mutually reinforcing.

Although they come from the discipline of organizational culture, they have a different meaning within HICS. They are divided according to their influence on the formalization of the relationship in mechanisms ex ante and ex post. The ex ante mechanisms condition the formation of the HIC by determining the energy that will be necessary for establishing that relationship. These mechanisms are the similarities of cultural practices and social embeddedness. Ex post mechanisms facilitate and enhance the interaction of actors in the network once the relationship is formed and they are tacit knowledge transfer and trust. 


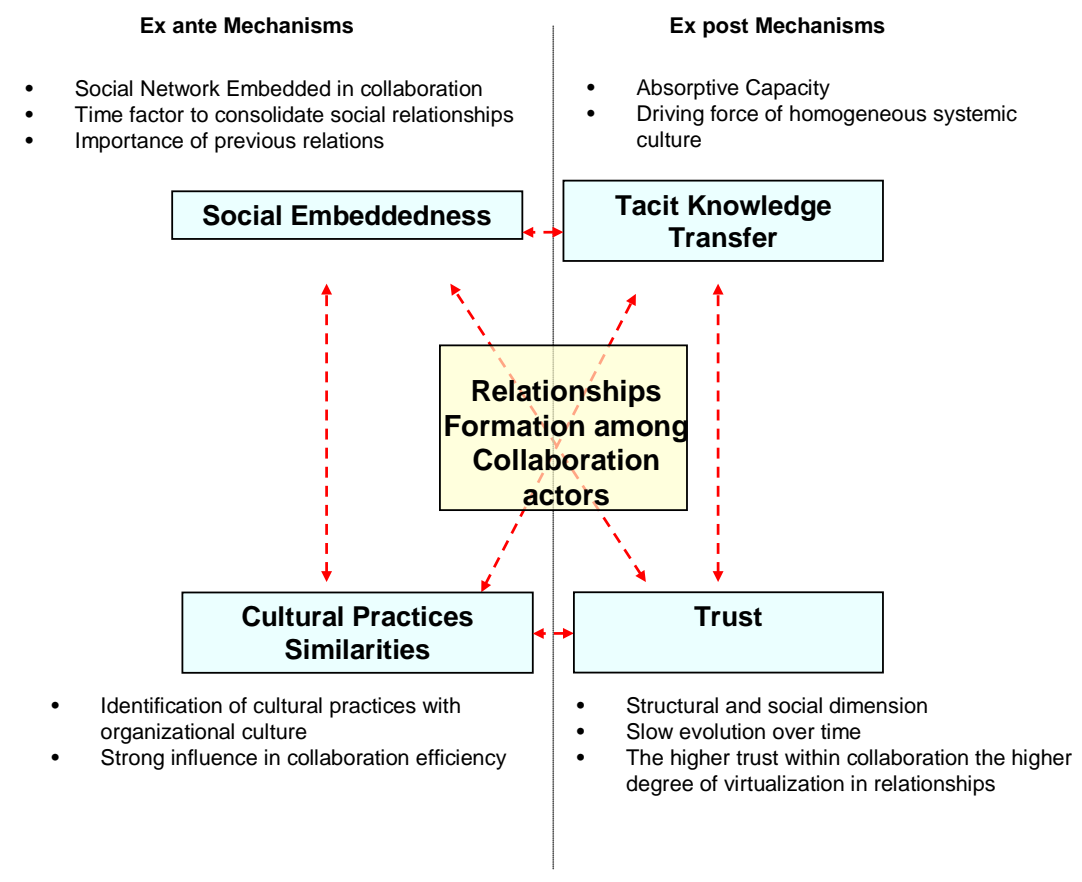

Figure 5. "Cultural mechanisms in horizontal inter-firm collaborations".

\subsection{Mutual influence of cultural mechanisms}

These four cultural mechanisms should not be seen as something static and independent but as dynamic mechanisms that continuously influence each other throughout the duration of the collaboration in an evolving process where they can go strengthening the relationship. For example, social embededness accelerates the exchange of tacit knowledge to improve the understanding, assimilation and cooperation (Uzzi, 1997). This mechanism facilitates the proper interpretation of knowledge, provides feedback means that ensure that the procedures have been interpreted correctly and that it is properly transferred. Tacit knowledge transfer in HICs is facilitated in many cases through strong relationships or social ties that promote a mutual learning process because it requires not only adequate absorption capacity but ability to overcome social barriers in the organization.

The interaction and influence between cultural similarities and tacit knowledge transfer is also a notorious in a HIC. Very large cultural differences between network actors can undermine the relationships and impede learning and knowledge transfer. The transfer of competencies and skills is more complex when cultural barriers are greater (Kogut, 1988). People with very different cultures have more trouble communicating, sharing their experiences and relying on each other 
(Carroll \& Teo, 1996). Also Cohen and Levinthal (1990) argue that absorptive capacity may differ among different actors in a network due to the different degree of cultural homogeneity among them. Dieter (2002) argues that knowledge transfer is inculcated within organizations through their organizational culture. It is therefore important that when two players interact they share a mutual understanding, a similar culture language and their social and personal characteristics are similar.

Although trust begins once the relationship is established (ex post mechanism) and develops over time, in many cases, social embeddedness underlying the business relationship tends to accelerate this process. An exception to this influence where high levels of trust may occur in the network without an intense process of socialization is the case of network actors with high reputation. Typically, managers of enterprises involved in an inter-firm collaboration will not transfer, unilaterally or bilaterally, individual tacit knowledge to other parties until a minimum level of trust has been reached. Trust also facilitates this process of sharing knowledge by creating a sense of security that knowledge will not be used beyond its primary objective (Fichman \& Levinthal, 1991). Similarities in cultural practices between HIC actors accelerate a rapid growth of social relations at both interpersonal and later at enterprise level and will be the perfect breeding ground for budding social network on which to base further business relations.

\subsection{Benefits of cultural mechanisms}

Cultural mechanisms greatly influence the formation and survival of HICs by exercising a number of cultural benefits seen before. A summary of these benefits are 1) easy integration of new members or collaborators in a HIC based primarily on social embeddedness, i.e. references or past experiences of one or more actors in the network, 2) increase of a homogeneous culture increasingly strengthened due mainly to the social network of relationships that were established, similarity of cultural practices and tacit knowledge transfer and 3 ) reduced transaction costs caused mainly by increased trust between network actors.

First steps in the formation of a HIC are complex. Network actors have great difficulty in obtaining information on needs and skills of potential new participants. This information is often confidential and not generally disclosed to anyone outside the organization. Social embeddedness of the companies involved in this process 
accelerates HIC mutual understanding by reducing the ambiguity in the information, also reducing the fear of opportunistic behaviour of potential partners.

The implicit assumption that large enterprise corporations or even external collaborations with capital participation (joint ventures) are more efficient than virtual collaborations is not necessarily true. Depending on the complementarity of resources, the initial stock of social commitment and trust, these virtual collaborations can become more efficient. Thus, the assumption of some authors (e.g. Williamson, 1985) that the degree of virtualization and monitoring costs are directly proportional is questionable. The incremental cost of managing a virtual collaboration increases partly due to the costs of supervision to avoid opportunistic behaviour. But an environment with intense activity of the four cultural mechanisms can significantly reduce transaction costs.

Following the approach of Williamson's transaction costs (1985), HICs emerge as a hybrid system where such costs are not high enough to justify the internalization of activities but, at the same time, they are not low enough to be subcontracted in the market. Throughout this work, we have seen how some cultural mechanisms such as social embeddedness or trust that can exert a very sensitive influence in reducing these costs. In fact, it might be the case that an activity is not profitable to outsource through a HIC because of its high transaction costs; it is so over time due to the effects of these cultural mechanisms by reducing transaction costs. In fact, under this approach, it should be reviewed the possibility of outsourcing to HICs most of the activities taking place internally.

Proposition 6: The degree of virtualization in HICs with strong activity of the four cultural mechanisms and transaction costs are not directly correlated.

Proposition 7: Under the perspective of transaction cost theory, non profitable collaborations with other HIC actors can become profitable due to the influence of cultural mechanisms.

Figure 6 represents the proposed conceptual model where the four cultural mechanisms interact with each other and influence the relations of the actors in HICs before and after the formalization of the collaboration. For the success of the relationship, from this cultural perspective, it is not necessary that all mechanisms have a strong activity but there is some harmony or synchronization between 
them. For example, a relationship between two actors with strong differences in their cultural practices can be successful if previously there is an intense activity of social relations between them. Or tacit knowledge transfer may be minimal in a successful relationship because the other mechanisms are intensively active. In the collaboration between GE and SNEMCA, cultural similarities are minimal but the intense activity of the other three cultural mechanisms supplied that lack.

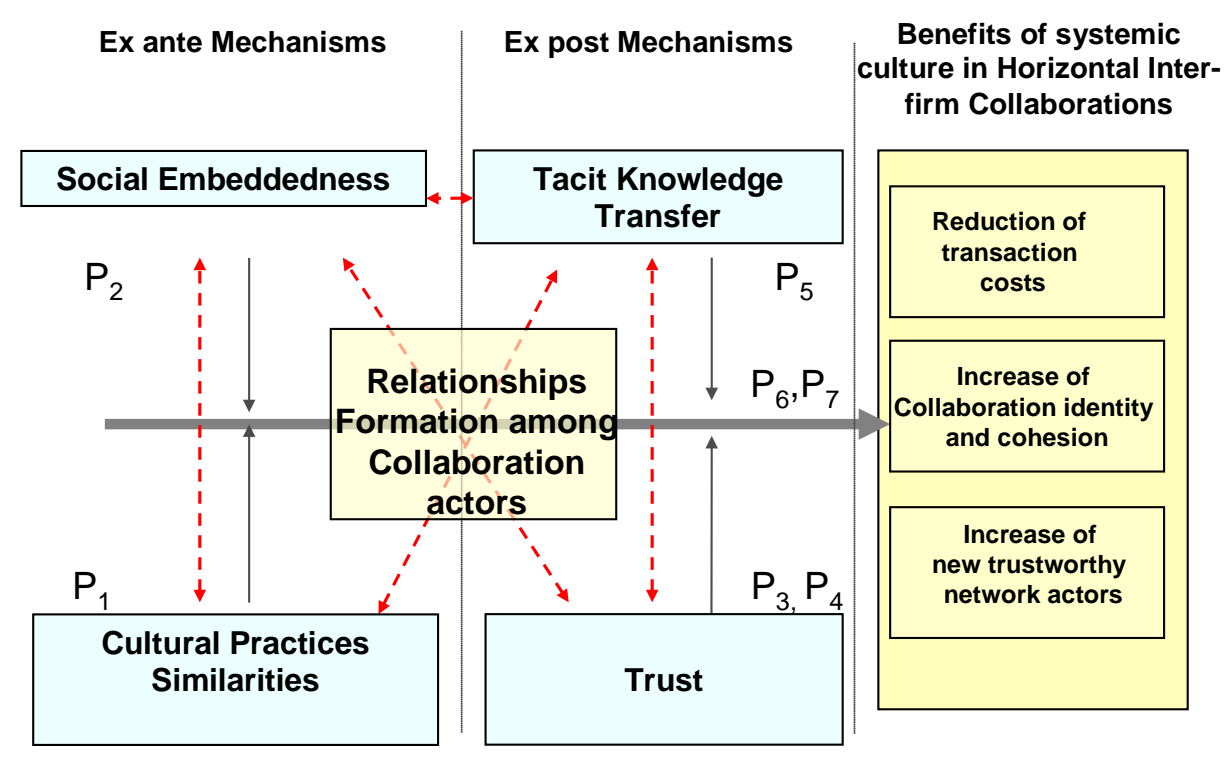

Figure 6. "Conceptual framework of systemic culture in HICs".

\section{Model validation}

\subsection{Methodology}

In order to validate the proposed framework of systemic culture, the case methodology will be applied to one of the most successful examples in the aeronautical industry on inter-firm collaboration between competing enterprises. This is the alliance between General Electric and SNECMA, a classical example of horizontal relationship, to manufacture the aircraft engine CFM 56.

Since little is known about how cultural mechanisms work in HICs with a comprehensive perspective, methodology used, according to Yin (1994), has been exploratory and descriptive based on a case study with qualitative approach. Exploratory studies are appropriate when the research problem is difficult to delimit, the problem is not well known and the available knowledge is not absolute. A qualitative case study approach has a distinct advantage when how or why 
questions is being asked about a contemporary set of events over which the researcher has little or no control. This qualitative approach based on a case study has been applied to the collaboration between GE and SNECMA due to the holistic character of systemic culture. Thus, it will permit to study this HICs phenomenon from the inside and gain a deeper understanding rather than a quantitative approach more convenient when clearly stated hypothesis can be tested on welldefined narrow studies (Yin, 1994). Therefore, this approach using the case method to the collaboration between GE and SNECMA will allow a detailed analysis of its culture through a real case for better understanding of the proposed model.

Data collected for this research work has been through interviews, literature review, documentation studies and on-site observations to achieve relatively high construct validity. Data were obtained through a number of visits, during six years (1999-2005), to the engine manufacturing plants of SNECMA (Evry-Corbeil, France) and GE Aero (Eskiseir, Turkey), where open interviews were carried out to relevant executives of these facilities. Additional methods of data collection were used to triangulate the data obtained from the interviews and on-site observation. These sources of data were a review of company documentation (annual reports, key financial data, shareholders information, catalogues and company web page), professional market reviews, specialized internet sites and literature reviewto achieve a high construct validity (Yin, 1994). Although this author also states that since case studies rely on analytical generalizations, which should try to generalize findings to theory, external validity should be high. However since this work only involves one case study, the ability to generalize is rather low. Thus more extensive case studies to other similar collaborations or to another industrial sectors where HICs are starting to grow to a great extent (e.g.: automotive or electronics industries) might stress the findings of this work in the future.

Williamson (1991), among others, argues that alliances between competitors are inherently temporary and unstable. These collaborations are doomed to fail in the long term especially with the risk of opportunistic behaviour by actors in search of short-term results without having to deal with expected long term uncertain returns. However, GE-SNECMA collaboration is a contradiction to this approach and a model in cooperation between direct competitors. Although the reasons for this strategic partnership were obvious, besides the technological, commercial and operational complementarities there were also many cultural aspects that strongly 
influenced the success of this relationship. This case is about the well known collaboration between GE and SNECMA under a new perspective based on the proposed systemic culture framework; a cultural perspective.

\subsection{GE-SNECMA collaboration}

General Electric (GE) and SNECMA are two of the largest aircraft engine manufacturers within the global market and although they are direct competitors, from the beginning, they clearly had a strategy of collaboration in manufacturing a mid-range engine in civilian industry to enter a promising market segment in which they were no present. Both partners had convergent strategic interests: competing with their common "enemy", Pratt \& Whitney, that for decades it was the leader of this market with its JT8D model and enter mid-range engine civilian market due to its enormous potential. GE was very interested in this collaboration because it represented a good opportunity to penetrate into the European market where he barely had any presence. In addition, he could avoid the strong competitive position that Pratt \& Whitney hold in the U.S. market. It also counteracted any European alliance around another major manufacturer, Rolls Royce, and took advantage of good relations of SNECMA with the European consortium Airbus, one its best potential customers. SNECMA also looked forward to this collaboration since it allowed him to acquire knowledge and experience in manufacturing, marketing and service in the civil aeronautical industry (Doz and Hamel 1998). In addition, there were strong technological complementarities; GE owned an important know-how in high-pressure components and engine combustion chamber while SNECMA had more experience in the compressor and low pressure turbine. There was also a strong commercial complementarity for GE and SNECMA since they had strong presence in North American and European markets and very weak in the other respectively.

The beginnings of the collaboration between General Electric, through its aeronautical subsidiary GE Aviation, and SNECMA started in 1960 and continue today. The first steps began with SNECMA minority participation in a program led by GE for the CF6 engine manufacturing. Subsequently, the collaboration continued in 1973 with the joint manufacture of the CFM56 engine, which has meant the most successful engine in the aeronautical industry for mid-range aircrafts. Contractual relations that were established with the joint manufacturing of CF6 
engine to power Douglas DC10 and Boeing 747 aircrafts was an opportunity for both sides to know each other, to share reasonable risks and evolve over time to a more personal or emotional context based on trust developed during those years.

In the early stages, this collaboration did not need much interaction from the two companies because of experience, knowledge and capacity of both partners enabled them to develop jointly the engine without high mutual dependency between the parties. The heart of the new CFM 56 engine would be based on the F101 engine developed by GE for the B1 bomber from the U.S. Air Force. SNECMA would provide the low-pressure system to convert the F101 in a new engine well adapted to the civilian industry. GE provided expertise in designing and manufacturing high-pressure compressor, high-pressure turbine and the combustion chamber while SNECMA was responsible for the low-pressure turbine, low-pressure compressor, lubrication systems, fuel and fan. Moreover, in order to avoid opportunistic behaviours, typical in the early stages of a collaboration when trust is not well developed yet, it was adopted a mechanism called "black box approach" whereby the contributions of intermediate products or subassemblies are brought into the alliance without disclosing the "know how" itself that contains the product (Zeng \& Chen, 2003). Therefore, to avoid any undesirable technology transfer, the main engine manufactured by GE, which covered much of the F101 military engine development was sealed before being sent to SNECMA for final adjustment (Dussauge $\&$ Garret, 1999). Then, once they started testing the engine and began to be in service, it required a greater mutual interaction to optimize its performance but by then the participants had learned to trust each other. The fact of not having to establish at the beginning a strong collaboration when trust between the two sides had not yet been consolidated, permitted to perfectly fit the growing need for interdependence with the growth of mutual trust through daily work and socialization.

Moreover, instead of approaching the alliance as a highly formalized process tightly regulated by a contract with strict clauses that controlled all processes, which was very normal in the military industry where GE and SNECMA were more focused, both parties understood to define new processes more responsive to the new spirit of collaboration within the civil industry. This collaboration was based from the beginning in a flexibility that allowed them to resolve incidents or resistance that arose over time. For example, GE and SNECMA periodically readjusted its profit- 
sharing formula because of unexpected changes in currency exchange or inflation, though they were not explicitly formalized in the contract (Lewis, 1990). Furthermore, in a first phase, both companies created new departments and new internal processes, identical in both companies, exclusively dedicated to the new program for developing the CFM engine. This measure allowed the formation of subcultures in these departments with high degree of cultural practices similarity between the two companies. Subsequently, it was created a $50-50 \%$ joint venture based in the United States at the headquarters of GE, but led by a French executive with a council made up of staff and directors of both companies. The president and Vice President were from SNECMA and the CFO and another executive Vice President were from GE. The staff team of directors of both companies should ratify all major decisions. This hierarchical management system allowed the alliance to control any type of contingency when it occurred and avoid opportunistic behaviour in a natural way.

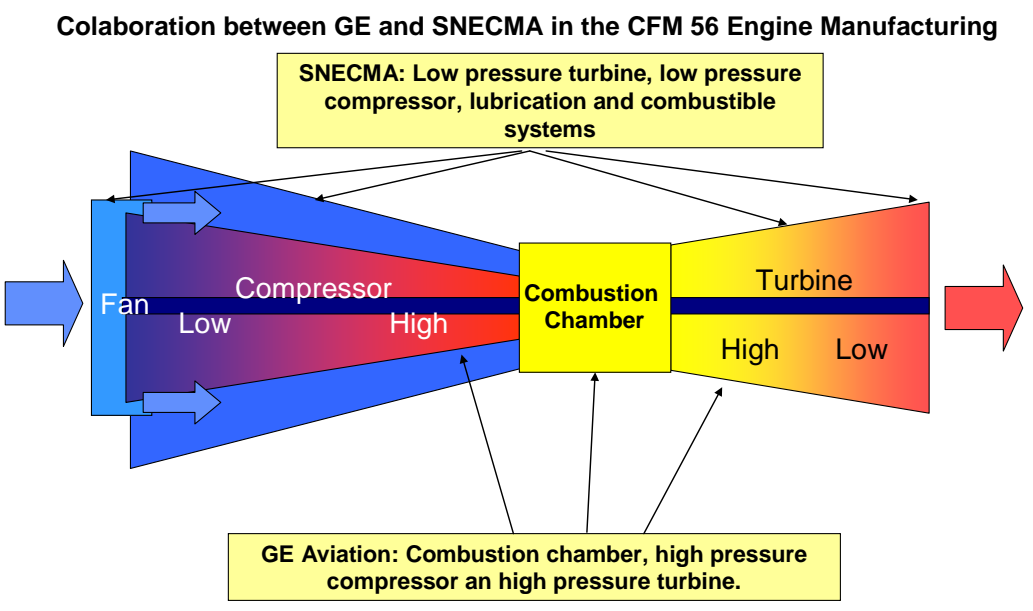

Figure 7. "Schematic of CFM 56 engine collaborative manufacturing between SNECMA and GE".

Since the beginning of the partnership, the senior management of GE and SNECMA showed a high commitment to the alliance so when more operational staff showed signs of resistance or potential opportunistic behaviour this tendency was soon interrupted by the senior management (Matta, 1992). Although they had moments of tension, structural complementarities and social quality of the relationship has enabled the alliance to survive until today. In fact, these conflicts strengthened the relationship by providing expertise to tackle future situations that were more complex without destroying the commitment in the project. 
Although the civilian market was not developed as expected in the years following the alliance since the oil crisis of the '70s, the clarity of the strategic objectives of the alliance and strong complementarily meant that both organizations showed strong institutional support. This support eventually resulted in an interpersonal trust that made them look both parties the best way to build up their own rules to develop cooperation, instead of relying on a rigid relationship based on a tightly regulated formal contracts, hardly plausible in the changing environment of that moment. This flexibility in the relationship permitted a strategic market refocus during the early years. The target market of mid-range aircraft, for which the engine was designed, had to be postponed due to the energy crisis to other more mature markets like in the old DC8 or the military version of Boeing 707. If the collaboration had been raised as more deterministic and rigid probably it would have lost this opportunity for strategic change and would have been cancelled the program.

As trust grew, knowledge transfer in both directions began to flow. SNECMA was acquiring experience and knowledge in civil engine manufacturing as well as in commercial functions within the civil engines market where most of customers were North Americans (Boeing and McDonnell Douglas). For its part, GE took advantage of good relations of SNECMA with the French government and Airbus. Over time, both partners developed increasingly a strategy of cospecialization where each company specialized in components or activities complementary to the other while stopped investing time and resources where there was overlap. This strategy had a high risk to specialize progressively more in a number of specific components complementary to the other partner, losing the overall view of the engine manufacturing. However, the great trust they had into each other based on a cumulative process of previous experiences made them to take the risk to become mutual hostages. Although cospecialization does not require an intensive knowledge transfer from the technological point of view, they also sought ways to improve the efficiency of the alliance beyond the initial scope of the collaboration agreement by sharing some developments in core technologies like composite materials for the blades of the turbines, manufacturing processes and management competencies (Doz, 1996).

Over time, GE-SNECMA relationship evolved into a cycle that enhanced and increased self-efficiency expectations. This cycle strengthened institutional 
commitments by both parties, deepening interpersonal trust, increasing the transfer of tacit knowledge, and gaining in flexibility and adaptability to new environmental conditions (Doz, 1996). The underlying basis of this relationship was made of a progressively intense social network of personal relationships that were eventually crystallizing into an inter-firm trust. Although there were several changes in the direction of the joint venture, key personnel from both organizations, loyal to the alliance, were maintained for long periods of time. Furthermore, both companies also made internal organizational changes to make their processes more compatible to the point that over time both companies were looking like each other.

The success of this collaboration was the result of an evolution that lasted many years. At first, the contractually prescribed organizational roles in the alliance were a warranty in the early stages of collaboration since trust was low and there were frequent misunderstandings. Although over time when interpersonal relations were more fluid and social networks more intense, these institutional roles were gradually disappearing since they started to be a constraint on the development of the alliance.

Soon, the alliance improved its efficiency and mutual trust grew. This scenario led them increasingly to make stronger and irreversible commitments as the expectations of the collaboration raised. Although there were also moments of tension, as the dilemma they faced when they had to decide between going as far as they could in the cospecialization by investing in progressively more specific assets or maintaining internally the capability to manufacture the complete engine but loosing the high potential of such complementary specialization. This strategy was especially risky for SNECMA who was the smaller partner of the alliance. The possible inability to manufacture a full aircraft engine could make him very vulnerable in the future. The dilemma was resolved by mutual agreement because of the presumed pressure it would exert the national military customer base to which both partners were hardly allowed to fully evolve to "cospecialization".

GE-SNECMA relationship has been one of the biggest hits of horizontal collaboration between competitors. Since the beginning, CFM 56 engine has become the most successful engine of the aeronautical industry with 19,000 engines produced to power over 7000 civil and military aircrafts including Boeing 
737 family and Airbus 320 . This collaboration has continued to expand over time to other engines of its range in the civilian industry as the GE 90 engine model or some engines models within the military industry.

\subsection{The importance of cultural collaboration mechanisms GE-SNECMA}

Although strategic convergence and technological, commercial and operational complementarities of this collaboration were evident also, under a cultural perspective, the adequate development of a set of measures facilitated this process as described in the proposed model. A key factor was the fact that there was no need for intense collaboration from the beginning but gradually grew over time. This process allowed social relations to consolidate in a smooth evolution. It started with the manufacturing program of the CF6 engine, which provided an opportunity for both sides to know each other and develop relationships. Gulati (1995) affirms the importance of previous relationships when establishing new alliances between network actors to stress the relevance of the social network that underlies the business relations. This aspect was ignored for many years by many scholars who relied on a more mechanistic perspective under the theory of transaction costs originally defended by Williamson (1985). Subsequently, the start of the GESNECMA joint venture did not require an intense collaboration because cospecialization approach permitted them to develop the engine components separately. Only in the final phase of assembly, the collaboration became more dependent but protection mechanisms such as the "black box" prevented opportunistic behaviour. Over time, as the social network became more intense, business collaboration strengthened and personal relationships and commitment between managers from both companies helped to solve any tense situation or conflict that arose during the collaboration.

Although there are no studies to support it, the cultural practices dissimilarities between GE and SNECMA were obvious. GE Avio is a subsidiary of an international corporation with multiple lines of business strongly diversified throughout the world with a clear focus in delivering value to his shareholders. While SNECMA, at that time, was a state-owned company engaged primarily in the aircraft engines manufacturing for the French military industry. Both players understood that if they wanted to succeed in this project, they needed to be away from their respective cultural practices existing at the time and find a meeting point more 
homogeneous from the organizational culture perspective. Therefore, they did not apply the existing procedures used mainly for the military industry but within each company, they defined a new ad hoc organizational context with new processes similar in both companies more in line to this project equally led by senior management of both organizations with a high degree of independence of their parent companies (Matta, 1992).

Moreover, tacit knowledge transfer allowed SNECMA to acquire business management and commercial skills specific of the aero engine civil industry as well as deeper knowledge about the high pressure compressor and turbine components. GE could establish close relations with the French government, which allowed becoming, through the CFM collaboration, the largest engines supplier for the European Airbus consortium.

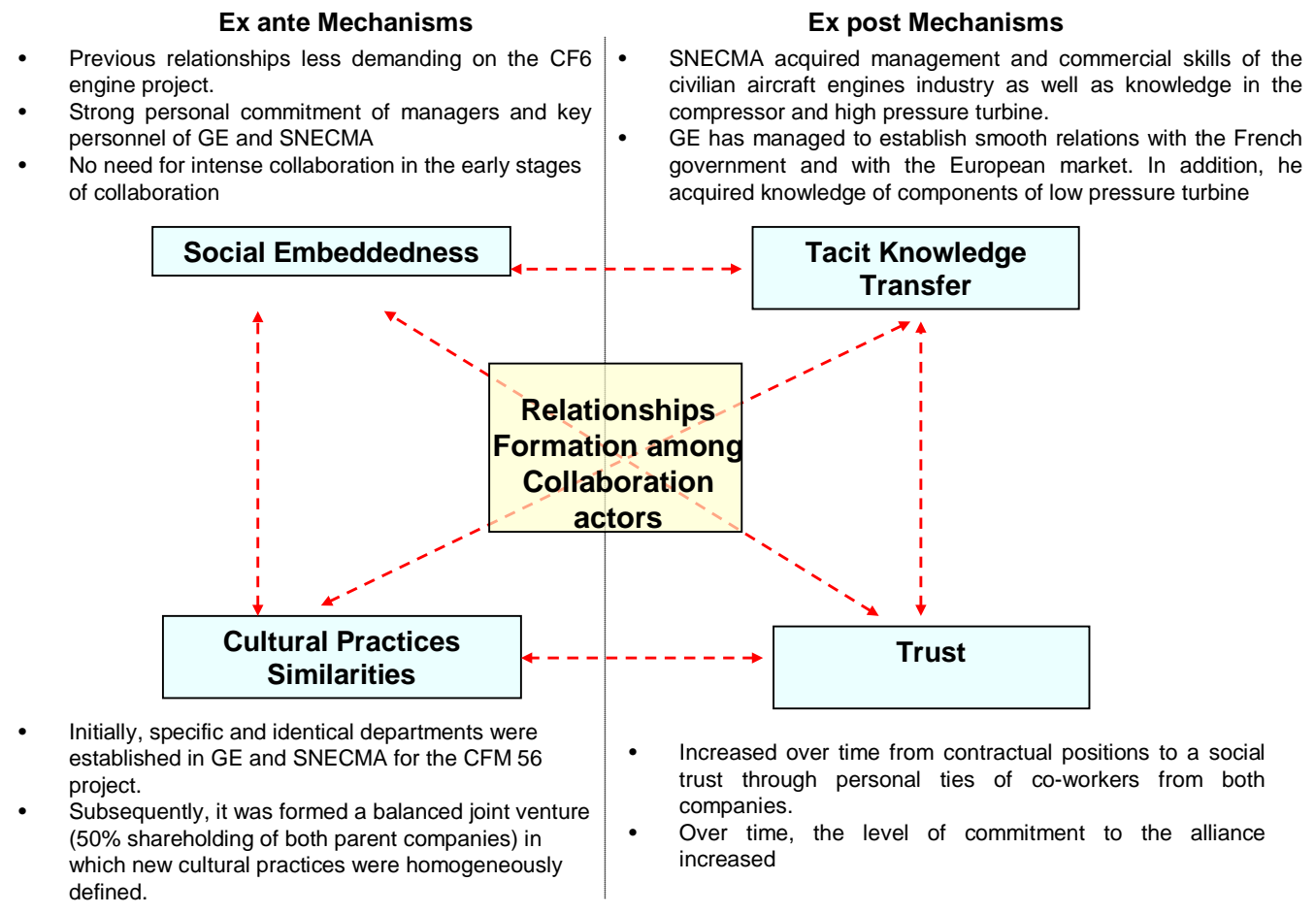

Figure 8. "Cultural mechanisms at GE-SNECMA collaboration to manufacture the CFM56 engine".

Trust was also an essential element in the success of this relationship. As personal relationships developed within the network, trust grew from formal or structural positions (Madhok, 1995) where emphasis was primarily focused on institutional 
roles and formal contracts towards a genuine trust among key people involved in the project and then at the corporate level. This type of trust is the one that has overcome all sorts of conflicts over the lifetime of the collaboration.

The benefits of these four cultural mechanisms were obvious since they permitted to reduce the transaction costs significantly as trust grew and the network of social relations between GE and SNECMA was consolidated. A network subculture was formed under the umbrella of the new joint venture CFMI. This factor facilitated the participation of other members in the network and the expansion of the GESNECMA collaboration to other programs such as the GE 90 engine, the CF6-80 engine or the cooperation in the consortium formed by GE Engine Alliance and Pratt \& Whitney in collaboration with SNECMA, GE, MTU, Techspace Aero and others. Figure 8 summarizes the most relevant aspects of cultural mechanisms in this collaboration.

\section{Discussion and conclusions}

The case of the GE and SNECMA collaboration clearly shows the importance of the cultural mechanisms proposed model. Although convergence of GE and SNECMA strategic objectives was clear, these four mechanisms greatly facilitated the collaboration. A priori, an alliance between competitors has many drawbacks due to the risk of opportunistic behaviour by actors in search of short-term results without having to deal with supposed returns in a long term uncertain stage. However, GESNECMA collaboration is a contradiction to this approach and a model to follow in the collaborations between direct competitors. While strategic reasons and complementarities of this collaboration were obvious, the importance of the four cultural mechanisms significantly influenced the success of this relationship.

These mechanisms directly helped the formation or survival of the relationship or had an indirect influence by interacting and enhancing the other mechanisms. They constitute the essence of a systemic culture in HICs. It is critical that those actors involved in HICs take into account the dynamics of these mechanisms in the same way they consider the most important factors of the traditional organizational culture to ensure the efficient functioning of their own organizations.

The proposed model should not be regarded as a deterministic and prescriptive proposal arising out of a set of rules or guidelines that any new participant in a HIC 
should meet, but requires a holistic view of the model where the four mechanisms interact and influence each other in formalizing and developing the collaboration. The key factor is the harmony and coordination of these four mechanisms throughout the relationship. This is because it has been used the case methodology as suggested by Yin (1994). For example, in most cases, differences in cultural practices of two or more companies working together is very common and hardly two companies will agree on the six types of cultural practices that proposes Hofstede et al. (1990). However, this limitation does not need to be an obstacle if certain patterns are taken into account. In the case of GE-SNECMA collaboration a number of new departments and internal processes were identically created in both companies exclusively dedicated to the new program for manufacturing the CFM engine. This measure allowed the formation of subcultures in these departments with high degree of similarity in their cultural practices. Or the subsequent formation of a new 50-50\% GE-SNECMA joint venture which facilitated the cultural compatibility in their practices. In other cases, the intense activity of the other cultural mechanisms can compensate the lack of one. Also, over time, the respective intensity of these mechanisms may be different if some degree of complementarity and harmony is accomplished. Therefore, since it can not be studied the whole casuistry of such partnerships, a holistic view of the model, as developed in this case study, allow better understanding of its dynamics.

However, this work presents a number of constraints to be addressed in the future. First, although Yin (1994) argues that research based on case methods allow theoretical generalizations of the results, being a single case, the capability to generalize is rather low and it will require additional studies to strengthen the results obtained in this work. This fact is especially relevant because of the case study applied in this work due to the specific nature of the aeronautical industry. Aspects like its high-end technology, the lead time to develop and manufacture new engines or the influence of other "stakeholders" like Public Administration or certification authorities may exert a significant influence on its actor behavior not applicable to other industrial sectors.

Second, partial validation of the propositions made should be complemented by future research using qualitative and quantitative methods. This is especially relevant in the case of the proposition P5 concerning the importance of tacit knowledge transfer as a homogenizing driver of systemic culture and propositions 
P6 and P7, which should be validated through quantitative methods. Second, perspective of this study was primarily focused on a dyadic relationship and although it seems clear the importance of cultural mechanisms under this perspective it is not sufficiently demonstrated the existence of a systemic and homogeneous culture in HICs. Finally, it would be very interesting to open the research field in two lines that would bring great value to this study; the first research line may be an analysis of HICs under other perspectives, like strategic, structural or dynamic perspectives including information and communication technologies at network level and its influence on these cultural mechanisms. The second research line, may be additional empirical studies of other industries, besides the aeronautical industry, where during last years these types of networks have grown to a great extend such as automotive, electronics and computers industry.

\section{References}

Ahuja, G. (2000). Collaboration Networks, Structural Holes, and Innovation: A Longitudinal Study. Administrative Science Quarterly, 45(3), 425-455. doi: $10.2307 / 2667105$

Barmeyer, C., \& Mayrhofer, U. (2008). The contribution of intercultural management to the success of international mergers and acquisitions: An analysis of the EADS group. International Business Review, 17, 28-38.

Beugelsdijk, S., Koen, C., \& Noorderhaven, N. (2009). A dyadic approach to the impact of differences in organizational culture on relationship performance. Industrial Marketing Management, 38, 312-323.

doi: 10.1016/j.indmarman.2008.02.006

Brown, L., Rugman, A., \& Verbeke, A. (1988). Japanese joint ventures with Western multinationals: synthesizing the economic and cultural explanations of failure. Journal of Pacific Asian Management, 6, 225-242.

doi: $10.1007 / B F 01733766$

Burt, R. (1992). Structural Holes: The Social Structure of Competition. Harvard University Press, Cambridge, MA. 
Camarinha-Matos, L. M., Afsarmanesh, H., Galeano, N., \& Molina, A. (2009). Collaborative networked organizations - Concepts and practice in manufacturing enterprises. Computers \& Industrial Engineering, 57(1), 46-60.

doi: 10.1016/j.cie.2008.11.024

Carroll, G. R., \& Teo, A. C. (1996). On the social networks of managers. Academy of Management J ournal, 38 (2), 421-440. doi: 10.2307/256786

Cartwright, S., \& Cooper, C.L. (1993). The Role of Culture Compatibility in Successful Organizational Marriage. Academy of Management Executive, 7 (2), 57-70.

Chen, X.P., \& Yao, X. (2003, August). Sustaining cooperation in public goods dilemmas: Effects of motivational explanations and sanctions. Paper presented at the annual meeting of the Academy of Management, Seattle.

Chituc, C.M., Toscazo, C., Azevedo, A. (2008). Interoperability in Collaborative Networks: Independent and industry-specific initiatives - The case of the footwear industry. Computers in Industry 59, 741-757.

doi: 10.1016/j.compind.2007.12.012

Cohen, W. M., \& Levinthal, D. A. (1990). Absorptive capacity: A new perspective on learning and innovation. Administrative Science Quarterly, 35, 128-152.

doi: $10.2307 / 2393553$

Deal, T. E., \& Kennedy, A. A. (1982). Corporate cultures: The rites and rituals of corporate life, Addison-Wesley Publishing Company, Reading, Massachusetts.

Dhanaraj, C., Lyles, M.A., Steensma, H.K., Tihanyi, L. (2002). Managing Tacit and Explicit Knowledge Transfer in IJVs: The Role of Relational Embeddedness and the Impact on Performance. Journal of International Business Studies, 35(5), 428442. doi: 10.1057/palgrave.jibs. 8400098

Dieter, E. (2002). Global Production Networks, Knowledge Diffusion, and Local Capability Formation, Research Policy 31 (8), 1417-1429.

doi: 10.1016/S0048-7333(02)00072-0 
Doz, Y. L. (1996). The Evolution of Cooperation in Strategic Alliances: Initial Conditions or Learning Processes? Strategic Management Journal 17, 55-83.

Doz, Y. L., \& Hamel, G. (1998). Alliance Advantage. Harvard Business Press.

Dussauge, P., \& Garrette, B. (1995). Determinants of Success in International Strategic Alliances: Evidence from the Global Aerospace Industry. Journal of International Business Studies, 26 (3), 505-530.

doi: $10.1057 /$ palgrave.jibs. 8490848

Fichman, M., \& Levinthal, D. A. (1991). Honeymoons and the liability of adolescence: A new perspective on duration dependence in social and organizational relations. Academy of Management Review, 16, 442-468.

doi: $10.2307 / 258870$

Granovetter, M. (1985). Economic Action and Social Structure: The Problem of Embeddedness. The American Journal of Sociology, 91 (3), 481-510.

doi: $10.1086 / 228311$

Gulati, R. (1995). Does Familiarity Breed Trust? The Implications of Repeated Ties for Contractual Choice in Alliances. The Academy of Management Journal, 38 (1), 85-122. doi: $10.2307 / 256729$

Gulati, R., \& Gargiulo, M. (1999). Where Do Interorganizational Networks Come From?. The American J ournal of Sociology, 104 (5), 1439-1493.

doi: $10.1086 / 210179$

Gulati, R., \& Nickerson, J. (2008). Interorganizational Trust, Governance Choice, and Exchange Performance. Organization Science, 19, 688-708.

doi: $10.1287 /$ orsc. 1070.0345

Gulati, R., \& Sytch, M. (2008). Does Familiarity Breed Trust? Revisiting the Antecedents of Trust. Managerial and Decision Economics, 29, 165-190. doi: $10.1002 /$ mde. 1396

Gupta, A. K., \& Govindarajan, V. (2000). Knowledge Flows within Multinational Corporations. Strategic Management Journal, 21 (4), 473-496.

doi: 10.1002/(SICl) 1097-0266(200004)21:4<473: : AID-SM] 84>3.0.CO;2-I 
Hofstede, G. (2009). The cultural relativity of organizational practices and theories

- Perspective. J ournal of International Business Studies, 40, 1589.

Hofstede, G., Neuijen, B., Ohayv, D., \& Sanders, G. (1990). Measuring Organizational Cultures: A Qualitative and Quantitative Study Across Twenty Cases. Administrative Science Quarterly, 35 (2), 286-316.

doi: $10.2307 / 2393392$

Hoopes, D. G., Madsen, T. L., \& Walker, G. (2003). Guest Editors Introduction to the Special Issue: Why is There a Resource-Based View? Toward a Theory of Competitive Heterogeneity. Strategic Management J ournal, 24, 889-902. doi: $10.1002 / \mathrm{smj} .356$

Johansen, K., \& Comstock, M. (2005). Coordination in collaborative manufacturing mega-networks: A case study. Journal of Engineering and Technology Management, 22 (3), 226-244. doi: 10.1016/i.jengtecman.2005.06.005

Kogut, B. (1988). Joint ventures: Theoretical and empirical perspectives. Strategic Management J ournal, 9, 319-332. doi: 10.1002/smj.4250090403

Lane, P., Salk, J., \& Lyles, M. (2001). Absorptive capacity, learning, and performance in international joint ventures, Strategic Management Journal 22, 1139-1161. doi: 10.1002/smj. 206

Larsson, R., Bengtsson, L., Henriksson, K., \& Sparks, J. (1998). The Interorganizational Learning Dilemma: Collective Knowledge Development in Strategic Alliances. Organization Science, 9 (3), 285-305.

doi: $10.1287 /$ orsc. 9.3 .285

Lavrac, N., Ljubic, P., Urbancic, T., Papa, G., Jermol, M., \& Bollhalter, S. (2007). Trust modeling for networked organizations using reputation and collaboration estimates. IEEE Transactions Systems, Man, and Cybernatics-Part C: Applications and Reviews, 37 3, 429-439.

Lewis, J. D. (1990). Partnerships for profit: Structuring and managing strategic alliances. New York: The Free Press. 
Li, R., Yu, T., \& Fang, M. (2004, July).The Reliability Management of Manufacturing Grid, CIMS and Robot Center. Paper presented at Flexible Automation and Intelligent Manufacturing Conference, FAIM 2004, Toronto, Canada.

Liu, Q., \& Shi, Y. J. (2008). Grid manufacturing for cross-enterprise. Int J Adv Manuf Technol, 36, 205-212. doi: 10.1007/s00170-006-0832-8

Luo, Y. (2001). Antecedents and Consequences of Personal Attachment in CrossCultural Cooperative Ventures. Administrative Science Quarterly, 46 (2), 177-201. doi: $10.2307 / 2667085$

Madhok, A. (1995). Revisiting Multinational Firms Tolerance for Joint Ventures: A Trust-Based Approach. Journal of International Business Studies, 26 (1), 117137. doi: $10.1057 /$ palgrave.jibs. 8490168

Matta, R.K. (1992). A Role Model for Internacional Alliances. Indian International Aeronautical Congress. Bombay.

Mayo, E. (1930). The Hawthorne Experiment, The Human Factor.

Meixell, M. J., Wu, S. D., \& Kamrani, A. K. (2004). Collaborative manufacturing for mass customization. Boston: Kluwer Academic Publisher.

Msanjila, S. S., Afsarmanesh, H. (2008). Trust analysis and assessment in virtual organization breeding environment. Internacional Journal of Production Research, 46 (5), 1253-1295. doi: 10.1080/00207540701224350

Nalebuff, B. J., \& Brandenburger, A. M. (1996). La competition, une révolution dans la manière de jouer concurrence et cooperation, Village Mondial, Paris.

Park, S.K., \& Ungson, G.R. (2001). Interfirm Rivalry and Managerial Complexity: A Conceptual Framework of Alliance Failure. Organization Science, 12 (1), 37-53. doi: $10.1287 /$ orsc. $12 \cdot 1 \cdot 37.10118$

Park, S. H., \& Ungson, G. (1997). The effect of partner nationality, organizational dissimilarity, and economic motivation on the dissolution of joint ventures. Academy of Management Journal, 39, 279-307. doi: 10.2307/256884 
Parkhe, A. (1993). The structuring of strategic alliances: A game- theoretic and transaction-cost examination of interfirm cooperation. Academy of Management Journal, 36, 794-829. doi: 10.2307/256759

Pettigrew, A. M. (1979). On studying organizational cultures. Administrative Science Quarterly, 24, 570-581. doi: 10.2307/2392363

Porter, M. (1996). What is Strategy?. Harvard Business Review, Nov-Dec.

Pothukuchi, V., Damanpour, F., Choi, J., Chen, C.C., \& Park, S.H. (2002). National and organizational culture differences and international joint venture performance. J ournal of International Business Studies, 33, 243-265.

doi: 10.1057/palgrave.jibs.8491015

Shapiro, D. L., Sheppard, B. H., \& Cheraskin, L. (1992). In theory: Business on a handshake. Negotiation J ournal, 8, 365-377.

doi: 10.1111/j.1571-9979.1992.tb00679.x

Schein, E.H. (1985). Organizational culture and leadership, Jossey Bass, San Francisco.

Steensma, K. \& Lyles, M. (2000). Explaining IJV survival in a transitional economy through social exchange and knowledge-based perspectives. Strategic Management J ournal 21, 831-852.

doi: 10.1002/1097-0266(200008)21:8<831:: AID-SMJ123>3.0.CO;2-H

Shi, Y., \& Gregory, M. (2003). From Original Equipment Manufacturers to Total Solution Providers: an emergence of Global Manufacturing Virtual Network in electronics industry. International Journal of Service Technology and Management, 4 (4), 331 - 346. doi: 10.1504/IJSTM.2003.003619

Sturgeon, J. (2002). Modular production networks: A new American model of industrial organization. Industrial and Corporate Change, 11 (3), 451-496. doi: $10.1093 / \mathrm{icc} / 11.3 .451$

Trice, H. M., \& Beyer, J. M. (1993). The cultures of work organizations, PrenticeHall, Englewood Cliffs, New Yersey. 
Uzzi, B. (1997). Social structure and competition in interfirm networks: the paradox of embeddedness. Administrative Science Quarterly 42, 35-67. doi: $10.2307 / 2393808$

Van de Ven, A. H. (1993). The institutional theory of John R. Commons: A review and commentary. Academy of Management Review, 18, 139-152. doi: $10.2307 / 258826$

Vilana, J. R., Rodríguez-Monroy, C. (2009a). Strategic Positioning of Global Manufacturing Virtual Networks in the Aeronautical Industry. Intangible Capital, 5 (2), 152-168. doi: 10.3926/ic.2009.v5n2.p152-168

Vilana, J. R., Rodríguez-Monroy, C. (2009b). Let Others Manufacture! Towards A New Manufacturing Framework. Intangible Capital, 5 (4), 347-369.

doi: 10.3926/ic. 2009.v5n4.p347-369

Williams, T., Ellis, B., Maull, R., Gregory, M. (2001, September). Offset Strategies in the Global Aerospace Sector. Paper presented at the 6th Research Symposium on International Manufacturing: Global Integration. Churchill College, Cambridge.

Williamson, O. E. (1991). Comparative economic organization: The analysis of discrete structural alternatives. Administrative Science Quarterly, 36, 269-296. doi: $10.2307 / 2393356$

Williamson, O.E. (1985). The Economics Institutions of Capitalism. Free Press, New York. 1991.FCE. México.

Yin, R.K. (1994). Case study research: design and methods. Thousand Oaks, CA: Sage Publications.

Zeng, M., \& Chen, X.P. (2003). Achieving Cooperation in Multiparty Alliances: A Social Dilemma Approach to Partnership Management Academy of Management Review, 28 (4), 587-605. doi: 10.2307/30040749 


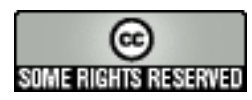

Article's contents are provided on a Attribution-Non Commercial 3.0 Creative commons license. Readers are allowed to copy, distribute and communicate article's contents, provided the author's and Journal of Industrial Engineering and Management's names are included. It must not be used for commercial purposes. To see the complete license contents, please visit http://creativecommons.org/licenses/by-nc/3.0/. 